\title{
INFLUENCE OF DOPING WITH Ni ON VISCOSITY OF LIQUID Al
}

\author{
S. Mudry, V. Sklyarchuk, A. Yakymovych \\ Faculty of Physics, Ivan Franko National University \\ 8, Kyryla i Mefodija St., Lviv, 79005, Ukraine
}

(Received October 04, 2006; received in final form January 22, 2007)

\begin{abstract}
The viscosity of $\mathrm{Al}_{1-x} \mathrm{Ni}_{x}(x=0.025 ; 0.05$ and 0.075$)$ molten alloys has been studied by means of oscillating crucible method. The temperature dependence of dynamical viscosity coefficient is obtained and activation energy is estimated from them. The analysis of concentration dependence of viscosity coefficient reveals its deviation from linear dependence. Significant increase of viscosity coefficient for liquid aluminum upon the addition of Ni-atoms is caused by cluster formation and increase of their size.
\end{abstract}

Key words: viscosity coefficient, activation energy, molten Al-based alloys.

PACS number(s): 66.20.+d, 83.85.Jn

\section{INTRODUCTION}

Aluminum based alloys are of great interest due to their practical use, especially in aircraft industry. For that reason the intensive research activity in studying aluminum alloys with other elements has been observed in recent years. In order to improve their physicalchemical properties which are responsible for such characteristics of practical importance as strength, plasticity, electroresistivity, hardness and corrosive resistivity, the doping with other elements and thermal treatment are commonly used. Particularly, the addition of rare earth elements to $\mathrm{Al}$ permits to obtain better mechanical properties. The effective improving of the above mentioned main characteristics of this metal can also be reached by addition of $3 d$-elements. Moreover, the addition of these metals and rare earth ones promotes the increase a glass forming ability. Therefore the studies of $\mathrm{Al}_{1-x} \mathrm{Ni}_{x}$ alloys in liquid state are of significant importance.

Earlier we investigated the structure of Al-enriched $\mathrm{Al}_{1-x} \mathrm{Ni}_{x}$ liquid alloys by means of $\mathrm{X}$-ray diffraction method [1]. It was found that addition of Ni-atoms to Al significantly changes the short range order and the structure of these liquid alloys deviates from those at random atomic distribution. The obtained data on diffraction studies allowed us to suggest that strong chemical interaction between $\mathrm{Al}$ and $\mathrm{Ni}$ atoms is the reason of structure change in liquid state. In order to confirm this suggestion and make clear the mechanism of Ni addition effect on the structure of liquid $\mathrm{Al}$ we use the viscosity measurement method.

$\mathrm{Al}-\mathrm{Ni}$ binary belongs to systems whose phase diagrams show the existence of chemical compounds and eutectic points [2]. Al-enriched alloys consist of two phases: $\mathrm{Al}+$ $\mathrm{Al}_{3} \mathrm{Ni}$. In solid state $\mathrm{Ni}$-atoms show a small solubility in aluminium ( $0.3 \%$ at the temperature of eutectic reaction $T=913 \mathrm{~K})$.

$\mathrm{Al}_{1-x} \mathrm{Ni}_{x}$ liquid alloys have been intensively studied through measuring various physical properties. It was shown [3] that a little addition of Ni-atoms does not significantly change the surface tension coefficient. On other hand, the viscosity data show an anomalous behavior. According to $[4,5]$ the viscosity coefficient slightly increases with addition of $\mathrm{Ni}$-atoms showing the maximum value at 0.3 at. $\% \mathrm{Ni}$. With the following addition of this element to $\mathrm{Al}$ it decreases and reveals the minimum value at eutectic composition (2.7 at.\% Ni). At a larger content of $\mathrm{Ni}$ this coefficient increases again showing the maximum value at equiatomic concentration.

Analyzing the available data on viscosity of $\mathrm{Al}$ and Al-based alloys one can conclude that there are discrepancies between them [6-10]. These discrepancies may be caused by oxide on the surface, which increase the value of viscosity coefficient. For that reason in [10] special care was takens to avoid such an effect. Neverthless new viscosity measurements are needed in order to arrive at certain conclusions about the viscosity change upon doping.

\section{EXPERIMENTAL}

There are a few methods to measure the viscosity of liquids: capillary, oscillating vessel, draining vessel, oscillating plate, rotational bob or crucible, levitation methods. Through technical difficulties having a lot of methods is not widely adopted. The capillary method, for example, has the following restrictions: temperature limit of about $1200{ }^{\circ} \mathrm{C}$, oxide inclusions; oscillating plate method - no slippage between the plate and the fluid, for low viscosity materials a thin oscillated plate must be vibrated slowly within the liquid, etc. The oscillating vessel method for the reason given above in most measurements of the viscosity is rather used.

In our studies the viscosity coefficient was measured using the oscillating crucible method. The results were obtained by means of oscillating-cup viscometer, where a cylindrical graphite crucible with a liquid sample undergoes rotation oscillations. For a right circular cylinder that is infinitely long containing a fluid the equation of motion of the damped cylinder can be written:

$$
I_{0}\left(\frac{d^{2} \theta}{d t^{2}}\right)+L\left(\frac{d \theta}{d t}\right)+f \theta=0
$$

where $I_{0}-$ moment of inertia of empty cup and suspension; $t$ - time; $L$ - damping term; $f$ - force constant 
of the torsion wire; $\theta$ - angular rotation in radians. The damping is a function of the viscosity of the liquid. The value of $\theta$ can be determined from:

$$
\theta=\theta_{m} \exp \left(\frac{-\delta t}{T}\right) \cos \left(\frac{2 \pi t}{T}\right)
$$

where $\theta_{m}$ - initial amplitude of harmonious oscillations; $T$ - time of complete oscillations; $\delta$ - logarithmic decrement. The viscosity of the liquid sample can be calculated by measuring both the decrement and the time period of oscillations.

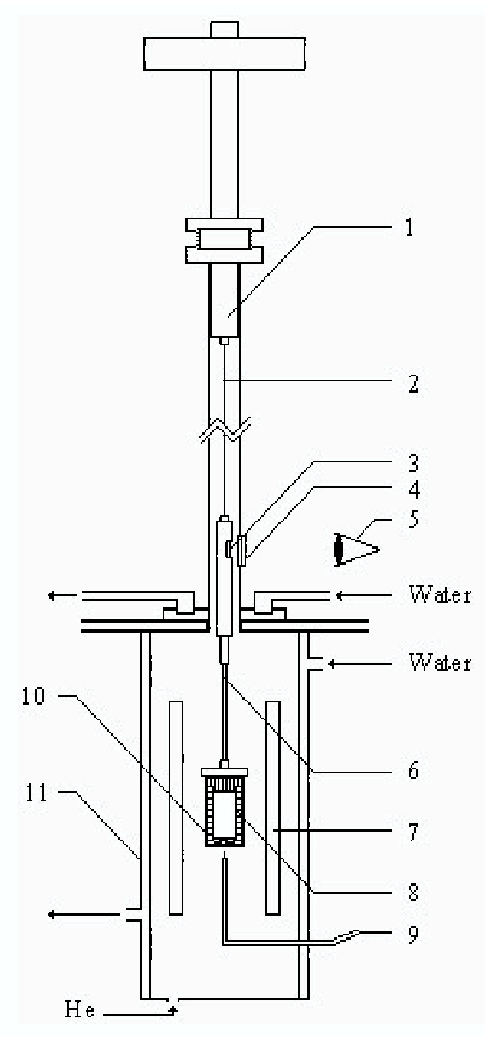

Fig. 1. Oscillating-cup viscometer.

Figure 1 shows the principal scheme of oscillating-cup viscometer which consists of:

- a steel chuck (1); molybdenum wire of $360 \mathrm{~mm}$ in length and $0.14 \mathrm{~mm}$ in diameter (2), suspension molybdenum rod (6), and the stainless steel container (10) with measuring crucible (8) inside. The latter is filled with a liquid sample;

- optical part containing laser, reflecting mirror (3) fixed at the stainless steel rod, window (4), photodiode (5);

- working part consisting of a furnace (7), thermocouple (9) and steel enclosure (11). The temperature was measured with the $\mathrm{Pt} / \mathrm{PtRh}$ calibrated thermocouple arranged just below $(7 \mathrm{~mm})$ the crucible and $22 \mathrm{~mm}$ below the melt. In order to avoid outer mechanical effects the viscometer is assembled on a separated massive bed. The furnace has a bifilar molybdenum heater. A set of radiation shields surrounds a heating area in order to avoid convective flows. Depending on the liquid sample properties, different crucibles (quartz or ceramic) with a diameter of $14 \mathrm{~mm}$ and $25 \mathrm{~mm}$ height can be used. In the case of strong liquid evaporation a crucible is provided by the cover.

The ingots of Al-Ni binary system, containing $0 ; 2.5$; 5 and 7.5 at.\% of $\mathrm{Ni}$ were prepared from pure $\mathrm{Al}$ and $\mathrm{Ni}$ of 99.99 purity by arc melting in a furnace filled with argon. The samples were placed into the chamber filled with helium of high purity. Values of viscosity coefficients were calculated from logarithmic decrements measured and with using the Shvidkovski equation [11].

$$
\eta=\frac{1}{\pi}\left(\frac{I}{m r}\right)^{2} \frac{\left(\delta-\delta_{0} \tau / \tau_{0}\right)^{2}}{\tau \sigma^{2}} \rho
$$

where $\eta$ - dynamic viscosity coefficient; $\delta_{0}, \tau_{0}, \delta, \tau-$ logarithmic decrement of damping and the oscillation period of the system without melt and with the melt, respectively; $I$ - moment of the system inertia; $m, r-$ mass and radius of the sample, respectively; $\sigma-$ correction coefficient; $\rho$ - density.

Measurements were carried out for three or four times at each temperature. The data error of different measurements at the same temperature was not more than $1 \%$. The accuracy of measurements was estimated to be less than $3 \%$.

\section{RESULTS AND DISCUSSION}

Temperature dependences of viscosity coefficient for $\mathrm{Al}_{1-x} \mathrm{Ni}_{x}$ molten alloys of different concentration are shown in Figure 2. As can be seen the experimental curves show the Arrhenius like behaviour that allows to suggest that there are no significant structure changes with temperature. In this figure the avaible data on temperature dependence of viscosity for alloy, containing 10 at.\% $\mathrm{Ni}$ is also represented for comparison [10]. This curve also confirms the existence of a tendency to viscosity increase upon addition of Ni-atoms to aluminum.

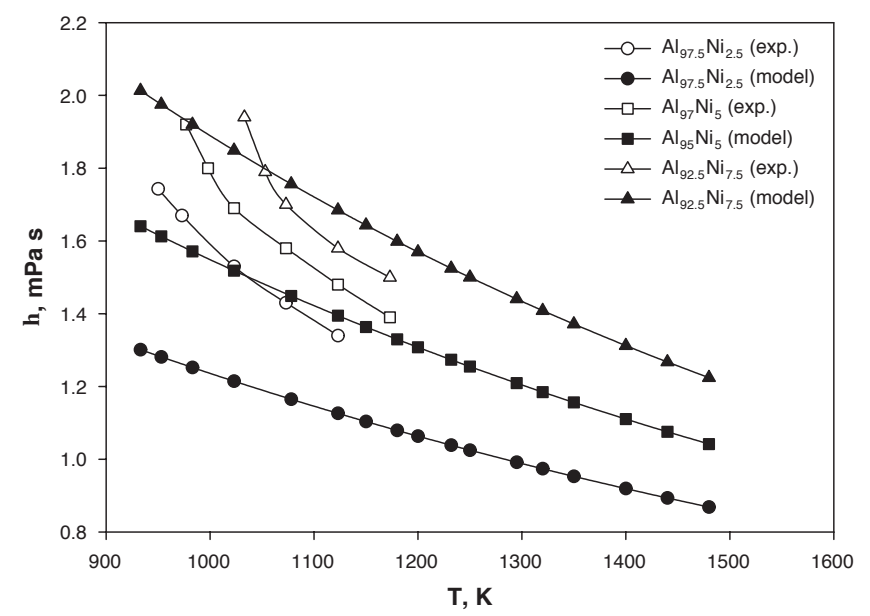

Fig. 2. Temperature dependence of viscosity coefficient for $\mathrm{Al}_{1-x} \mathrm{Ni}_{x}$ melts. 
The concentration dependences of viscosity at three temperatures are represented in Fig. 3. This figure shows that $\eta$ significantly increases upon addition of 2.5 at. $\%$ $\mathrm{Ni}$ and it is in fact unchangeable up to 7.5 at.\% Ni. The rapid increase of viscosity for alloy containing 10 at.\% of $\mathrm{Ni}$ is attributed to change in structure and chemical bonding. Taking into account the profile of equilibrium phase diagram the existence of atomic microgroups, whose sructural motif is similar to the structure of $\mathrm{Al}_{3} \mathrm{Ni}$ and AlNi chemical compounds was suggested. Analyzing the data on thermodynamic and other physical properties $[3,12]$ which show the extreme point near AlNi stoichiometric concentration, one can suppose the preference for the influence of AlNi associates on the structure of concentrated melts. This suggestion is in accordance with the model of associates which is commonly used for the interpretation of thermodynamic data [13]. It should be noted also that our data are in disagreement with the results obtained in [4]. The results of our experiment show an increase of viscosity coefficient with concentration whereas in [4], as was above mentioned, the existence of maximum and minimum points within this concentration range was indicated. Therefore the experimental data on viscosity concentration dependences show the anomalous behaviour and should be interpreted in the frame of existing models.

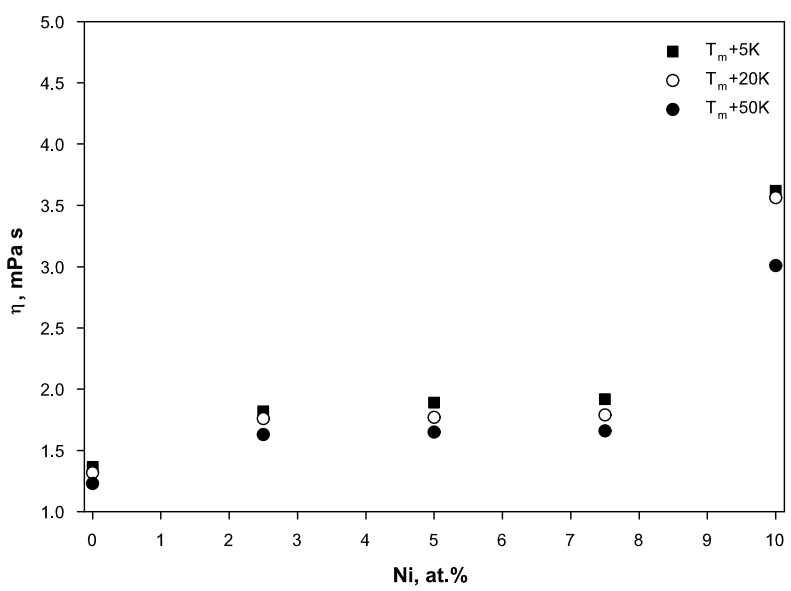

Fig. 3. Concentration dependence of viscosity coefficient for $\mathrm{Al}_{1-x} \mathrm{Ni}_{x}$ melts.

At first we have calculated the viscosity coefficients using the hard sphere model and corrections to it [14]. Temperature dependences of viscosity calculated according to this and nother models in comparison with experimental data are shown in Fig. 2. The accounting of corrections to additive part of viscosity yields an increase in the slope of its temperature dependence. Nevertheless as can be seen from Fig. 2, the hard sphere model shows the discrepancy with experimental data. A most probable reason of this discrepancy is no accounting of attractive part in the formula for a hard sphere potential. We have taken into account the corrections in order to avoid this discrepancy:

$$
\eta=\eta^{\mathrm{id}}+\Delta \eta
$$

$\eta$ - viscosity coefficient of liquid; $\eta^{\text {id }}-$ viscosity coefficient of liquid in case of ideal solution; $\Delta \eta$ - excess viscosity, which can be written in the following way:

$$
\Delta \eta=\Delta \eta_{H}^{\sigma}+\Delta \eta_{H}^{M}+\Delta \eta_{S}
$$

where $\Delta \eta_{H}^{\sigma}$ - hard sphere part contribution to viscosity, which is the function of atomic diameter difference:

$$
\Delta \eta_{H}^{\sigma}=-\alpha\left(x_{1} \eta_{1}+x_{2} \eta_{2}\right)\left(\frac{x_{1} x_{2}\left(\sigma_{1}-\sigma_{2}\right)}{x_{1} \sigma_{1}^{2}+x_{2} \sigma_{2}^{2}}\right)
$$

where $\eta_{1}, \eta_{2} ; \mathrm{x}_{1}, \mathrm{x}_{2} ; \sigma_{1}, \sigma_{2}$ - viscosity coefficients of elements, atomic fractions and hard sphere diameters respectively; $\alpha$ - parameter $\left(\alpha=5 \cdot 10^{-2}\right)$.

$\Delta \eta_{H}^{M}$ - hard sphere contribution to viscosity, which depends on nuclear mass difference of components:

$$
\begin{aligned}
\Delta \eta_{H}^{M} & =-\beta\left(x_{1} \eta_{1}+x_{2} \eta_{2}\right) \\
& \times\left(\left(\frac{x_{1} x_{2}\left(M_{1}^{1 / 2}-M_{2}^{1 / 2}\right)^{2}}{\left(x_{1} M_{1}^{1 / 2}+x_{2} M_{2}^{1 / 2}\right)^{2}}\right)^{1 / 2}-1\right)
\end{aligned}
$$

where $M_{1}, M_{2}$ - nuclear masses of components; $\beta$ parameter $\left(\beta=2 \cdot 10^{-2}\right)$.

$\Delta \eta_{S}$ - soft component of viscosity, which is determined by an attractive part in theinteratomic potential. Its contribution to exceed viscosity can be estimated by means of Moelwyn-Hughes's equation [15]:

$$
\Delta \eta_{S}=-\gamma\left(x_{1} \eta_{1}+x_{2} \eta_{2}\right) x_{1} x_{2} \Delta H /(R T)
$$

where $\Delta H$ - enthalpy of mixing; $\gamma-$ parameter $(\gamma=$ $\left.6 \cdot 10^{-4}\right)$.

Enthalpy of mixing value, which is needed for these calculations, was taken from [16]. One can see from Figure 2 that taking into account these corrections reduces a discrepancy between the calculated and experimental data. Hence, this fact allowed us to suppose that chemical interaction should be accounted in the analysis of experimental data on viscosity concentration dependence.

Considering the viscosity as a characteristic which displays the glass forming ability of alloys we can conclude that addition of $\mathrm{Ni}$ to $\mathrm{Al}$ promotes the ability to form a glass by rapid quenching from melt.

Experimental data on viscosity versus temperature were used to calculate the activation energy $E$ by fitting to Arrhenius equation:

$$
\eta=A \exp ^{E /(R T)} .
$$

For liquid aluminum this value was calculated to be $14.23 \mathrm{~kJ} / \mathrm{mol}$. Addition of $\mathrm{Ni}$ atoms (2.5 at.\%) leads to some decrease of activation energy. With the next addition of $\mathrm{Ni}$ to alloy ( 5 at.\%) the activation energy increases. Comparatively less value of activation energy is observed at the concentration, corresponding to eutectic point $(2.7$ at. $\% \mathrm{Ni}$ ) in phase diagram (Table 1$)$. 


\begin{tabular}{|c|c|c|c|c|}
\hline$x$, at. $\%$ & 0 & 2.5 & 5 & 7.5 \\
\hline \hline $\mathrm{E}_{\eta}, \mathrm{kJ} / \mathrm{mol}$ & 14.23 & 12.66 & 12.99 & 13.12 \\
\hline
\end{tabular}

Table 1. Activation energy values for liquid $\mathrm{Al}_{100-x} \mathrm{Ni}_{x}$ alloys.

As is well known from Frenkel [17] and Eyring [18] theory of viscous flow the activation energy is proportional to interaction forces between neighbor atoms. Consequently, the effective interaction forces between any two atoms irrespective of their sort is less for melt of eutectic concentration.

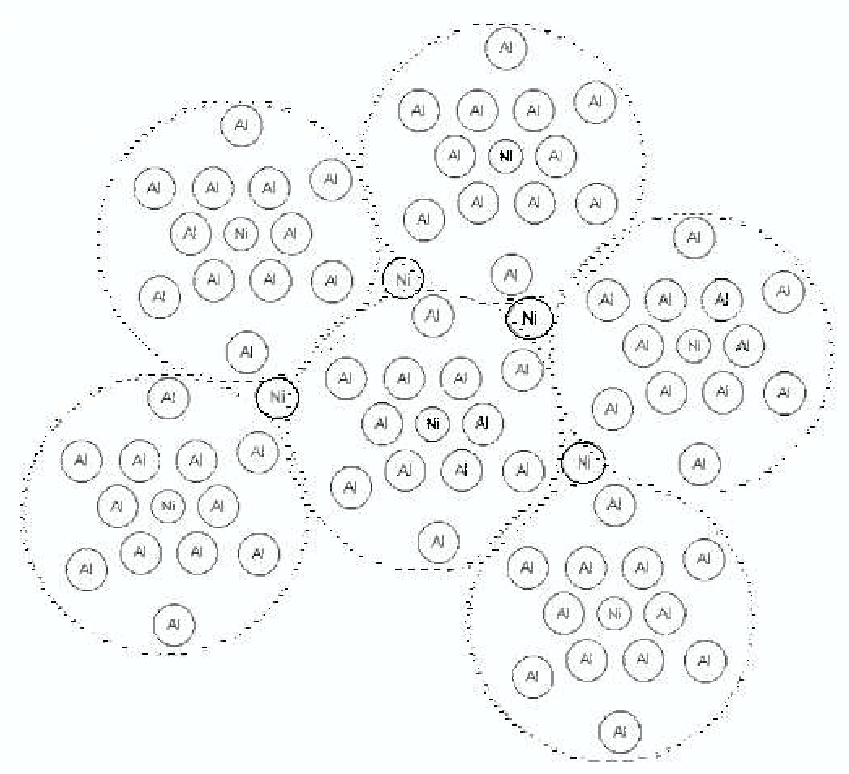

Fig. 4. Model of atomic aggregation in molten $\mathrm{Al}$ doped with $\mathrm{Ni}$.

It should be also noted here that increase of viscosity of liquid $\mathrm{Al}$ doped with $\mathrm{Ni}$ in comparison with the one for pure $\mathrm{Al}$ can be attributed to a decrease of atomic movement. Such reducing of atomic mobility occurs due to increase of chemical bonding between nickel and nearest Al-atoms. These facts, obtained from the analysis of experimental data on viscosity allowed us to propose the cluster model in order to explain the influence of $\mathrm{Ni}$ on viscosity of Al. Taking into account the microinhomogeneous structure of liquid metals in the temperature region not far from melting point, we suppose that diluted Ni-atoms are randomly distributed in Al-matrix. Due to strong $\mathrm{Ni}-\mathrm{Al}$ chemical interaction these atoms attempt to have Al-atoms as neighbours. Hence the formation of dynamical clusters of $\mathrm{Al}$ atoms centred by $\mathrm{Ni}$-ones oc- curs in a molten alloy. The larger values of viscosity for $\mathrm{Al}_{1-x} \mathrm{Ni}_{x}$ molten alloys is suggested to be caused both by an increase of interaction between unlike kind atoms and cluster formation. At a higher content of Ni-atoms some of them can also link few clusters in aggregated groups of more size (Fig. 4). Consequently the change of viscosity of $\mathrm{Al}$ with addition of $\mathrm{Ni}$ is caused by achange in structure because the Ni-atoms attempt to complete their $d$-band.

When the content of Ni-atoms becomes larger the interaction between them and Al-ones leads to the changes in total atomic distribution and as a result the transformation of Ni-centered clusters into chemically ordered distribution occurs. For that reason the maximum value of viscosity in $\mathrm{Al}-\mathrm{Ni}$ binary system corresponds to equiatomic composition [19]. Therefore there are two mechanisms of viscosity increase at different concentration regions. At a small content of $\mathrm{Ni}$ the viscosity increases due to the formation of Ni-centered dynamical clusters and their cooperation, whereas in molten alloys with a larger content of $\mathrm{Ni}$ it shows a higher value due to chemical ordering in short range order structure.

This fact is in agreement with a profile of phase diagram which reveals the preferred interaction between similar atoms near eutectic point, and between unlike ones within concentration range corresponding to chemical compounds. Our results on viscosity allowed us to find that similar tendency occurs also in the liquid state. Therefore one can conclude that chemical ordering which is more pronounced for melts with a higher content of $\mathrm{Ni}$ is suggested to be the main reason for observed viscosity and activation energy change. We suggest also that due to the preferred interaction between $\mathrm{Al}$ and $\mathrm{Ni}$ atoms the $\mathrm{Al}_{1-x} \mathrm{Ni}_{x}$ associates are responsible for the viscosity changes of neareutectic molten alloys. The content of $\mathrm{Al}$ and $\mathrm{Ni}$ in such chemically ordered structural units can vary within some wide range. This range is supposed to be significantly wider than the homogeneity range for solid AlNi compound.

\section{CONCLUSIONS}

The viscosity of Al-Ni liquid alloys, containing 2.5; 5; 7.5 at.\% $\mathrm{Ni}$ shows an increase with the addition of $\mathrm{Ni}$ atoms. Such a behavior of viscosity coefficient is motivated mainly by the formation of Al-clusters centred by $\mathrm{Ni}$ atoms and their cooperation. The observed feature at neareutectic concentration is supposed to be caused by a transition of the cluster structure to the chemically ordered one.
[1] S. Mudry, T. Lutsyshyn, J. Alloys Comp. 367, 289 (2004)

[2] Binary Alloy Phase Diagrams, 2nd edition, edited by T. Massalsky (ASM International, Ohio, 1990).

[3] L. F. Mondolfo, Aluminum Alloys: Structure and Prop- erties (Butterworths, London, 1976).

[4] W. R. D. Jones, W. L. Bartlett, J. Inst. Met. 81, 145 (1952-53).

[5] A. M. Korol'kov, Casting Properties of Metals and Alloys 
(Consultants Bureau, New York, 1960).

[6] A. T. Dinsdale, P. N. Quested, J. Mater. Sci. 39, 7221 (2004).

[7] T. P. Yao, V. Kondic, J. Inst. Met. 81, 17 (1952-53).

[8] E. Rothwell, J. Inst. Met. 90, 384 (1960).

[9] E. Gebhardt, M. Becker, S. Dorner, Z. Metall. 44, 510 (1953).

[10] T. Yamasaki, S. Kanatani, Y. Ogino, A. Inoue, J. NonCryst. Solids 156-158, 441 (1993).

[11] E. G. Shvidkovski, Nekotorye voprosy vyazkosti rasplavlennych metalov (State Publishing House for Technical and Theoretical Literature, Moscow, 1955).

[12] R. Hultgren, P. D. Desai, D.T . Hawkins, M. Gleiser, K. K. Kelly, Selected Values of the Thermodynamic Properties of Binary Alloys (Metals Park, American Society of Metals, Ohio, 1973).

[13] F. Sommer, Z. Metallkd. 73, 72 (1982).

[14] Liquid Metals. Third International Conference on Liquid Metals, edited by R. Evans, D. A. Greenwood (The Institute of Physics, Bristol and London, 1976).

[15] E. A. Moelwyn-Hughes, Physical Chemistry 2nd edition (Pergamon, Oxford, 1961).

[16] A. K. Niessen, A. R. Miedema, F. R. de Boor, R. Boom, Physica B 152, 303 (1988).

[17] J. Frenkel, Kinetic Theory of Liquids (Dover, New York, 1955).

[18] S. Glasstone, K. J. Laidler, H. Eyring, The Theory of Rate Processes (McGraw-Hill, New York, 1941).

[19] M. S. Petrushevsky, E. S. Levin, P. V. Held, Russian J. Phys. Chem. 12, 3035 (1971).

\title{
ВПЛИВ ДОМІШоК Ni НА В'ЯЗКІСТЬ РІДКОГО Al
}

\author{
С. Мудрий, В. Склярчук, А. Якимович \\ Фізичний факультет, Національний університет імені Івана Франка \\ вул. Кирила і Мефоділ, 8, Лъвів, 79005, Україна
}

\begin{abstract}
В'язкість розплавів $\mathrm{Al}_{1-x} \mathrm{Ni}_{x}(x=0.025 ; 0.05$ та 0.075$)$ досліджено методом крутильних коливань. Отримано температурні залежності коефіцієнта динамічної в'язкости й оцінено енергію активації. Аналіз концентраційної залежности коефіцієнта в'язкости вказує на її відхилення від лінійної залежности. Значне зростання в'язкости зумовлено формуванням кластерів на основі атомів Al, у центрі яких є атоми Ni. Kрім того, в'язкість зростає внаслідок збільшення розмірів структурних одиниць і посилення хемічної взаємодії між алюмінієм і нікелем.
\end{abstract}

